Jurnal Scripta Teologi dan Pelayanan Kontekstual
ISSN
ISSN
Http://ejournal.stte.ac.id
Vol.4, No.1, pp. $33-49,2020$

\title{
Merajut Anugerah Dalam Penginjilan Holistik
}

\author{
Aris Elisa Tembay, Elimanc \\ 'STT Ebenhaezer Tanjung Enim, Aristembay@gmail.com \\ ${ }^{2}$ STT Ebenhaezer Tanjung Enim, Elimanandef@gmail.com
}

\section{INFO ARTIKEL}

Sejarah Artikel:

Diterima : 07 Mei 2019

Direvisi : 15 Mei 2019

Disetujui: 23 Mei 2019

Dipublikasi: 28 Mei

2019

Kata Kunci:

Merajut, Anugerah,

Penginjilan, Holistik.

Keywords:

keyword one, keyword two, keyword three.

\section{ABSTRAK}

Kejatuhan manusia kedalam dosa telah membuat manusia kehilangan kemuliaan Allah. Manusia bukan saja harus menerima hukuman Allah secara rohani sebagai mahluk yang diciptakan dengan Kemuliaan Allah, namun secara fisik dan social mereka menerima ganjaran hukuman dari Allah. Kehidupan secara fisik berubah, dimana mereka kemudian menyadari bahwa dirinya dalam keadaan telanjang dan merasakan malu. Secara social mereka mengalami putusnya hubungan dengan Allah dan lingkungannya kemudian menjadi takut dan menyembunyikan diri dari hadapan Allah. Manusia kemudian menerima hukuman dari Allah yang berdampak secara rohani, dan juga jasmani. Mereka dibuang dari tempat kemuliaan kedalam dunia yang penuh dengan penderitaan sebagai akibat dari perbuatan dosa tersebut. Allah kemudian menunjukkan Kasih-Nya, dengan mencari manusia yang telah jatuh dalam dosa mengadakan pemulihan, akan tetapi tetap menegakkan keadilan dengan menjatuhkan hukuman-Nya dan mengadakan perjanjian akan Keselamatan bagi manusia berdosa. Rancangan keselamtan dari Allah inilah yang kemudian dilaksankan dengan Misio-Dei, dimana Allah mengutus Anak-Nya Yesus Kristus datang kedunia ini, para Nabi dan Rasul, kemudian Misio Eklesiae, dimana Allah menempatkan Gereja-Nya dan mengutus orang-orang percaya untuk memberitakan Injil Keselamatan. Injil Keselamatan itu adalah "Kabar Baik" dimana didalamnya ada berita tentang kelepasan manusia dari hukuman dosa. Dosa telah membuat manusia mengalami berbagai penderitaan, baik rohani, Jasmani juga hubungan berdampak pada lingkungan social. Pemulihan tidak hanya cukup pada tataran Rohani saja, karena dosa adalah permasalahan yang kompleksitas dan menyeluruh dalam kehidupan manusia didunia ini. Pelayanan "Holistik" adalah upaya untuk memulihkan keberadaan manusia seutuhnya, baik secara spiritual dimana manusia diperdamaikan dengan Allah tetapi juga secara mental dimana manusia dibangkitkan kembali semangatnya untuk memperjuangkan kehidupannya didunia ini. Dengan demikian Injil bukan saja menyelesaikan perkara-perkara rohani saja, akan tetapi juga berdampak pada kehidupan social masyarakat, karena itulah tugas Gereja untuk melakukan tiga hal penting dalam dunia ini: Marturia, Koinonia, dan Diakonia. Inilah merupakan bagian dari pelayanan yang bersifat "Holistik" 


\section{ABSTRACT}

Man's fall into sin has made man lose the glory of God. Humans must not only receive God's punishment spiritually as a creature created with the Glory of God, but physically and socially they receive punishment from God. Life physically changes, where they then realize that they are naked and feel ashamed. Socially, they experience a break with God and their environment and become afraid and hide themselves from God. Humans then receive punishment from God that impacts spiritually, and also physically. They are banished from the place of glory in a world full of suffering as a result of these sins. God then shows His love, by searching for people who have fallen into sin to make restoration, but still uphold justice by dropping His punishment and entering into a covenant of Salvation for sinful humans. This salvation design from God was then carried out by Misio-Dei, where God sent His Son Jesus Christ to come into this world, the Prophets and Apostles, then Misio Eklesiae, where God placed His Church and sent believers to preach the Gospel of Salvation. The Gospel of Salvation is the "Good News" in which there is news about human deliverance from the penalty of sin. Sin has caused people to experience various sufferings, both spiritual, physical and also the relationship has an impact on the social environment. Restoration is not only enough at the Spiritual level, because sin is a complex and comprehensive problem in human life in this world. "Holistic" service is an effort to restore the whole human existence, both spiritually where humans are reconciled with God but also mentally where humans are reawakened to fight for their lives in this world. Thus the Gospel not only resolves spiritual matters, but also has an impact on the social life of the community, because that is the Church's duty to do three important things in this world: Marturia, Koinonia, and Diakonia. This is part of the service that is "Holistic".

\section{Pendahuluan}

Kata 'holistik' dalam Kamus Besar Bahasa Indonesia mempunyai pengertian “ciri pandangan yang menyatakan bahwa keseluruhan sebagai suatu kesatuan lebih penting dari pada satu-satu bagian dari suatu organisme". Istilah pelayanan yang holistik saat ini memang banyak digunakan oleh berbagai kalangan untuk menunjukkan bentuk pelayanannya, namun ada juga kelompok orang yang salah mengartikannya. Sering terjadi salah pengertian mengenai pelayanan holistik adalah anggapan bahwa pelayanan holistik adalah pelayanan yang berbentuk pelayanan sosial, sehingga akhirnya ada yang mengartikan bahwa pelayanan holistik adalah pelayanan sosial. Pemahaman akan pelayanan yang holistik diungkapkan Herlianto sebagai pelayanan yang mencakup pemberitaan Injil baik secara verbal maupun secara perbuatan dan ditujukan untuk menjangkau manusia seutuhnya pula, yaitu manusia yang terdiri dari tubuh, jiwa dan roh, dan manusia yang mempunyai kaitan-kaitan sosial, budaya, ekonomi, hukum dan politik dengan lingkungannya.

Jika pelayanan holistik dianggap sebagai pelayanan gereja yang menyeluruh maka pelayanan tersebut harus mencakup semua aspek pelayanan yang dilakukan oleh gereja. J.C. Hoekendijk mengatakan bahwa pelayanan holistik yang meliputi unsur-unsur pelayanan : Koinonia (persekutuan), Martyria (kesaksian), dan Diakonia (pelayanan sosial), merupakan hal yang mutlak menggarisi penginjilan dan 
mendatangkan syalom (damai sejahtera, keselamatan) yang dijanjikan Tuhan. Tomatala mengatakan tentang hakikat misi yang holistik dimana dapat dijelaskan sebagai "satu yang menyeluruh" yang memiliki kesatuan integral dengan aspek-aspek lengkap yang utuh. Pemberitaan Injil menyentuh aspek pelayanan dasar pada empat dimensi pelayanan yang holistik yaitu : Persekutuan (koinoneo), Pelayanan (diakoneo), Kesaksian (martureo) dan Pemberitaan (kerigma/kerusso).

Sedangkan Istilah Evangelisasi sendiri berasal dari bahasa Yunani, dari kata kerja Ev $\alpha \nu \gamma \in \lambda \iota \zeta$ o $\mu \iota \iota$ dalam bentuk kata kerja, dari kata benda "Euangelion".

Kata "Euangelican” berarti: 'Kabar Baik' atau 'Injil' (Rm. 10:16; Mat. 4:23; 9:35; 24:14; 26:13). Selain itu, dapat juga diterjemahkan dengan istilah 'berita Injil' (Ef. 3:6; Fil. $1: 7 ; 27 b)$

Kata “Euangelizomai” berarti: 'memberitakan kabar baik' (Mat. 11:5; Luk. 7:22), 'menyampaikan kabar baik' (Luk. 19, 4:18; I Pet. 1:25), 'membawa kabar baik' (Rm. 10:15), 'memberitakan kabar kesukaan' (Kis. 13:32; Ibr. 4:2,6). Istilah ini menunjuk kepada suatu pekerjaan yang bertujuan membawa orang lain kepada pengenalan dan penerimaan akan Injil serta menuntunnya kepada pertobatan.

Dalam arah pengertian yang sama, dengan "Euangelizomai", akhirnya kegiatan tersebut mendapat pembedaan dalam bahasa Inggris menjadi "Evangelisation" yang berarti pemberitaan Injil (II Kor. 8:18; Gal. 2:7), atau 'pekabaran Injil' (Fil. 4:3), sekarang ini lebih dikenal dengan istilah 'penginjilan'. Orang yang melakukan pemberitaan Injil disebut pemberita Injil atau penginjil (Kis. 21:8; Ef. 4:11; II Tim. 4:5). Oleh karena Injil atau kabar kesukaan tersebut datangnya dari Allah, maka kabar ini adalah kabar kesukaan yang luar biasa menyenangkan dan menyukakan hati. Kabar yang memberikan informasi penting bagi perubahan hidup dan keselamatan umat manusia, sebab Allah telah datang ke dalam dunia di dalam Yesus Kristus untuk menggenapkan perjuangan Allah dalam upaya menyelamatkan umat manusia seperti yang telah dinyatakan-Nya di taman Eden (Kej. 3:15). Karya salib Yesus menjadi penggenapan akan hal itu dalam hal perwakilan kurban pengampunan dosa dan kurban keselamatan seperti yang digambarkan dalam perwujudan hukum Taurat sebagai kurban pengganti diri umat manusia yang harus nmati karena dosa dan kesalahannya.

Dengan demikian, pengampunan yang diberikan Allah kepada manusia, bukanlah pengampunan yang berdasar kasih belaka, tetapi pada kasih dan keadilan Allah. Karena kasih Dia mau mengampuni kita dan karena keadilan, maka pengampunan itu harus dibayar dengan harga tebusan. Inilah kabar kesukaan itu, bahwa kita diberikan pengampunan dosa dan keselamatan berdasarkan harga yang telah dibayar oleh Yesus Kristus melalui pengurbanan diri-Nya di atas kayu salib sebagai kurban pengganti diri umat manusia. Oleh karena itu, setiap orang yang percaya kepada-Nya diberikan pengampunan dosa dan keselamatan kekal secara cuma-cuma tetapi dengan harga yang sangat mahal, yaitu harga Yesus Kristus sebagai pencipta.

Jadi, pengampunan dan penerimaan Allah terhadap orang percaya, terjadi atas karya penebusan oleh Yesus Kristus. Dialah yang telah menanggung hukuman Allah ganti manusia berdosa, sehingga setiap orang yang telah menerima Yesus Kristus sebagai Tuhan dan Juru selamat pribadinya, berarti menerima karya penebusan Yesus Kristus atas dirinya. Inilah yang disebut sebagai Anugerah Allah, yaitu pemberian keselamatan secara Cuma-Cuma kepada setiap orang percaya kepada Tuhan Yesus Kristus. 
Pelayanan holistik juga seringkali dijadikan alat untuk meredam suatu gejolak dimasyarakat ketika terjadi aksi karena ketidaksukaan masyarakat atas kehadiran orang Kristen, atau juga sebagai alat untuk menenangkan masyarakat ketika terjadi aksi protes terhadap pembangunan gereja. Kelihatannya memang efektif namun sebenarnya kondisinya tetap seperti api dalam sekam yang sewaktu-waktu api tersebut bisa membesar. Ini adalah suatu perbuatan yang kelihatannya baik tetapi bukan dilandasi oleh kasih yang murni, karena seolah-olah seperti ada "udang dibalik batu". Jika kita melakukan hal tersebut bukankah dapat dikatakan kita melakukan "suap yang terselubung dengan kedok kasih", apa yang membedakannya dengan tindakan orang-orang non Kristen.

Kebanyakan orang beranggapan dan mempraktekkan pelayanan holitik sebagai bagian dari penginjilan, atau dilakukan dengan tujuan penginjilan dimana akhirnya bisa menjadi "penginjilan terselubung", padahal seharusnya penginjilan itulah yang justru merupakan bagian dari pelayanan holistik. Kalau kita melayani hanya sebagai "umpan” agar ikan-ikan mau mengigit kail kita, maka secara etis teologia tindakan ini tidak jujur, tidak murni. Yang paling fatal adalah ketika ternyata kita hanya menjadikan dan memperlakukan sesama sebagai "objek" untuk dijaring tanpa adanya rasa kasih. pelayanan holsitik bertujuan pada kesejahteraan manusia seutuhnya, artinya memberitakan Injil yang penuh kepada manusia yang utuh dalam berbagai dimensi, Kejadian 2 : 7 memberi kesaksian yang sangat jelas bahwa manusia adalah debu (adam). Allah menciptakan menjadi tubuh materi dan Allah amat memperhatikan kebutuhan fisik manusia dengan memberi makanan kepada manusia. Manusia adalah jiwa (psyche) yang mempunyai kebutuhan-kebutuhan kejiwaan. Allah amat memperhatikan kebutuhan kejiwaan manusia, Allah tidak membiarkan manusia kesepian (Kej 2: 18), manusia diberikan kebebasan (Kej 2: 16) bahkan dikarunia kepercayaan dan tanggung jawab (Kej $2: 15$ ). Manusia adalah roh. Allah memberikan nafas hidup, bahkan menghebuskan itu dari nafas hidup Allah sendiri (Kej 2: 7). Karena itu pelayanan holistik harus memperhatikan semua dimensi ini, yaitu spiritual, psikis dan fisik manusia.

Pelayanan holistik berupaya untuk memulihkan keseimbangan dan kesarasian antara dimensi individualitas dan sosial manusia. Oleh karena itu dalam pelayanan holistik tidak dikenal dikotomi atau pemisahan antara kebutuhan individual dan sosial manusia. Tidak seharusnya ada pertentangan antara "individual gospel" (kaum vertikalis) dan "social gospel" (kaum horisontalis). Oleh karena itu pelayanan holistik seharusnya juga melayani manusia dalam bidang sosial, ekonomi, budaya, politik dan sebagainya. Pelayanan holistik berupaya untuk memulihkan keseimbangan dan kesarasian antara keduanya. Tujuan dari pelayanan holistik bukan hanya untuk kepentingan manusia tetapi kepentingan seluruh lama ciptaan. Manusia memang diberi mandat untuk berkuasa atas alam (Kej 1:26), tetapi manusia juga diberi tugas untuk memelihara alam (Kej 2:15) dan bukan memusnahkannya. Pelayanan holistik tidak boleh hanya "people oriented" tetapi "life oriented", usaha menjadikan seluruh alam semesta "theatrum gloriae dei” (Calvin). Kata 'holistik' dalam Kamus Besar Bahasa Indonesia mempunyai pengertian "ciri pandangan yang menyatakan bahwa keseluruhan sebagai suatu kesatuan lebih penting dariPada satu-satu bagian dari suatu organisme".

Berdasarkan pengertian kata holistik diatas maka istilah 'pelayanan yang holistik' adalah pelayanan yang bersifat menyeluruh, tidak terbagi-bagi. Pelayanan 
yang memandang, memahami, mendekati dan memperlakukan manusia sebagai satu keseluruhan yang utuh. Ini merupakan sebuah pengakuan bahwa hakikat manusia adalah memang terdiri atas unsur-unsur dan aspek-aspek yang berbeda-beda (multidimensional), namun demikian kepelbagaian itu tidak dipahami sebagai yang bersiafat dikhotomis (dapat dipisah-pisahkan atau saling dipertentangankan) ataupun hirarkis (seolah-olah ada unsur yang lebih penting Atau lebih mulia dari unsur lainnya).

Istilah pelayanan yang holistik saat ini memang banyak digunakan oleh berbagai kalangan untuk menunjukkan bentuk pelayanannya, namun ada saja kelompok orang yang salah mengartikannya. Salah pengertian yang paling sering mengenai pelayanan holistik adalah anggapan bahwa pelayanan ini adalah pelayanan yang berbentuk pelayanan sosial, sehingga akhirnya ada pengertian bahwa pelayanan holistik adalah pelayanan sosial.

\section{Metode Penelitian}

Dalam penulisan ini penulis menggunakan metode deskriftif-bibliologis. Metode deskriftif adalah suatu metode penelitian yang meneliti sekelompok manusia, suatu objek, suatu kondisi, suatu sistem pemikiran ataupun suatu kilas peristiwa masa sekarang.

Ada pun tujuan penelitian ini adalah untuk memuat deskripsi, gambaran atau lukisan secara sistematis, faktual dan akurat mengenai fakta-fakta, sifat-sifat serta hubungan antar fenomena yang diteliti.

Selain itu tujuan dari penelitian ini untuk mengumpulkan data, gambaran, penegasan suatu konteks atau gejala serta sesuatu pertanyaan hubungan dengan status subjek penelitian saat ini. Pengumpulan data dilakukan dengan cara penelitian, menganalisis literatur dan untuk mendapatkan data yang lebih lengkap.

\section{Hasil Dan Pembahasan \\ Pemahaman Pelayanan Holistik}

Sebagian besar orang melihat pelayanan holistik sebagai aktivitas yang pertama dari usaha penanaman gereja, berbentuk respon bagi kebutuhan fisik dan sosial dari masyarakat. Sebagian lagi memulai dengan visi dari transformasi individu dan masyarakat dalam seluruh bagian kehidupan -spiritual, ekonomi dan sosial dan kemudian megembangkan sebuah strategi yang selaras dengan visi itu.

Kelompok yang memulai dengan visi dari transformasi mengakui bahwa ada hubungan dari semua area kehidupan. Pelayanan yang dilakukan harus terintegrasi dan mereka mengakui bahwa berita Injil adalah lengkap yaitu isi berita dan dampaknya. Kelompok ini melihat bahwa tema dari Kerajaan Allah adalah pelayanan holistik. Kerajaan Allah merupakan isi dari berita Injil dan harus membawa dampak pada seluruh bagian kehidupan manusia.

Pemahaman akan pelayanan yang holistik diungkapkan Herlianto sebagai pelayanan yang mencakup pemberitaan Injil baik secara verbal maupun secara perbuatan dan ditujukan untuk menjangkau manusiasutuhnya pula, yaitu manusia yang terdiri dari tubuh, jiwa dan roh, dan manusia yang mempunyai kaitan-kaitan sosial, budaya, ekonomi, hukum dan politik dengan lingkungannya. Jika pelayanan holistik dianggap sebagai pelayanan gereja yang menyeluruh maka pelayanan tersebut harus mencakup semua aspek pelayanan yang dilakukan oleh gereja. J.C. Hoekendijk 
mengatakan bahwa pelayanan holistik yang meliputi unsur-unsur pelayanan: Koinonia (persekutuan), Martyria (kesaksian), dan Diakonia (pelayanan sosial), merupakan hal yang mutlak menggarisi penginjilan dan mendatangkan syalom (damai sejahtera, keselamatan) yang dijanjikan Tuhan.

Hal yang sama diungkapkan Tomatala tentang hakikat misi yang holistik dimana dapat dijelaskan sebagai "satu yang menyeluruh" yang memiliki kesatuan integral dengan aspek-aspek lengkap yang utuh. Pemberitaan Injil menyentuh aspek pelayanan dasar pada empat dimensi pelayanan yang holistik yaitu: Persekutuan (koinoneo), Pelayanan (diakoneo), Kesaksian (martureo) dan Pemberitaan (kerigma/kerusso).

Dalam organisasi Gereja Bethel Indonesia maka pelayanan holistik jelas harus meliputi tujuh aspek yang ada dalam tugas-tugas gereja, yaitu: Marturia (kesaksian dan pemberitaan Injil), Koinonia (persekutuan), Diakonia (pelayanan kasih), Didaskalia (pendidikan), Leiturgia (ibadah), Pastoralia (pengembalaan) dan Poimenoia (penatalayanan).

\section{Tujuan Pelayanan Holistik}

Tujuan akhir dari misi adalah penanaman gereja baru. Kelompok pertama yang memperlihatkan bahwa iman mereka mengakui Kristus sebagai Tuhan dan Juruslamat mewujudkannya dalam persekutuan dan kesaksian.

Pelayanan holistik seringkali, tetapi tidak selalu, dipaksakan sebagai alat untuk penanaman gereja di kelompok masyarakat yang miskin. Jadi pelayanan holistik diterima sebagai hal yang sangat berguna dan kadang-kadang sangat efektif untuk penanaman gereja.

Pelayanan holistik juga seringkali dijadikan alat untuk meredam suatu gejolak dimasyarakat ketika terjadi aksi karena ketidaksukaan masyarakat atas kehadiran orang Kristen, atau juga sebagai alat untuk menenangkan masyarakat ketika terjadi aksi protes terhadap pembangunan gereja.

Kelihatannya memang efektif namun sebenarnya kondisinya tetap seperti api dalam sekam yang sewaktu-waktu api tersebut bisa membesar. Ini adalah suatu perbuatan yang kelihatannya baik tetapi bukan dilandasi oleh kasih yang murni, karena seolah-olah seperti ada "udang dibalik batu". Jika kita melakukan hal tersebut bukankah dapat dikatakan kita melakukan "suap yang terselubung dengan kedok kasih", apa yang membedakannya dengan tindakan orang-orang non Kristen.

Kebanyakan orang beranggapan dan mempraktekkan pelayanan holitik sebagai bagian dari penginjilan, atau dilakukan dengan tujuan penginjilan dimana akhirnya bisa menjadi "penginjilan terselubung", padahal seharusnya penginjilan itulah yang justru merupakan bagian dari pelayanan holistik.

Kalau kita melayani hanya sebagai “umpan” agar ikan-ikan mau mengigit kail kita, maka secara etis teologias tindakan ini tidak jujur, tidak murni. Yang paling fatal adalah ketika ternyata kita hanya menjadikan dan memperlakukan sesama sebagai "objek" untuk dijaring tanpa adanya rasa kasih.

Harus diingat bahwa pelayanan holsitik bertujuan pada kesejahteraan manusia seutuhnya, artinya memberitakan Injil yang penuh kepada manusia yang utuh dalam berbagai dimensi, yaitu manusia sebagai kesatuan pneuma-psikologi-somatis. Kejadian 2: 7 memberi kesaksian yang sangat jelas bahwa manusia adalah debu (adama). Allah menciptakan menjadi tubuh, materi dan Allah amat memperhatikan kebutuhan fisik manusia dengan memberi makanan kepada manusia. Manusia adalah jiwa (psyche) 
yang mempunyai kebutuhan-kebutuhan kejiwaan. Allah amat memperhatikan kebutuhan kejiwaan manusia, Allah tidak membiarkan manusia kesepian (Kej $2: 18$ ), manusia diberikan kebebasan (Kej $2: 16$ ) bahkan dikarunia kepercayaan dan tanggung jawab (Kej 2 : 15). Manusia adalah roh. Allah memberikan nafas hidup, bahkan menghebuskan itu dari nafas hidup Allah sendiri (Kej $2: 7$ ).

Karena itu pelayanan holistik harus memperhatikan semua dimensi ini, yaitu spiritual, psikis dan fisik manusia.Dimensi yang lain adalah dimensi individualitas dan sosial manusia.

Kemanusiaan manusia akan terganggu ketika hanya salah satu aspek saja yang ditekankan. Pelayanan holistik berupaya untuk memulihkan keseimbangan dan kesarasian antara keduanya. Oleh karena itu dalam pelayanan holistik tidak dikenal dikotomi atau pemisahan antara kebutuhan-kebutuhan individual dan sosial manusia. Tidak seharusnya ada pertentangan antara "individual gospel" (kaum vertikalis) dan "social gospel” (kaum horisontalis). Oleh karena itu pelayanan holistik seharusnya juga melayani manusia dalam bidang sosial, ekonomi, budaya, politik dan sebagainya.

Pelayanan holistik juga memperhatikan dimensi kekinian dan keakanan. Ini berarti kita bukan hanya memperhatikan kebutuhan-kebutuhan mendesak yang ada sekarang, tetapi juga kepentingan masa depan. Hal ini bisa mempunyai makna pemenuhan kebutuhan dalam kehidupan di dunia sekarang dan di akhirat nanti namun juga berarti memperhatikan kepentingan dan kesejahteraan generasi-generasi yang akan datang.

Ada satu dimensi lagi yaitu dimensi manusia dan lingkungan. Pada mulanya Allah menciptakan langit dan bumi (Kej 1:1) dan Allah melihat segala yang dijadikanNya itu sungguh amat baik (Kej 1:31). Tujuan dari pelayanan holistik bukan hanya untuk kepentingan manusia tetapi kepentingan seluruh lama ciptaan. Manusia memang diberi mandat untuk berkuasa atas alam (Kej 1:26), tetapi manusia juga diberi tugas untuk memelihara alam (Kej 2:15) dan bukan memusnahkannya. Pelayanan holistik tidak boleh hanya "people oriented" tetapi "life oriented", usaha menjadikan seluruh alam semesta "theatrum gloriae dei" (Calvin).

\section{Misi Holistik Menurut Alkitab}

Dalam bagian ini penulis akan membahas tentang : Pengertian Misi Holistik menurut Alkitab, dimana didalamnya akan dibahas mengenai Kasih Allah yang bersifat universal, Manifestasi Kasih Yesus bagi segala suku bangsa, dan dasar Eskhatologis

\section{Pengertian Misi Holistik}

Secara hurufiah kata holistic memang tidak terdapat dalam Alkitab, namun pengertian kata ini tercakup dalam arti kata Shalom dalam bahsa ibrani yang mencakup tiga ide : Keseluruhan, kesejahteraan dan harmoni. Arti dasar S 29:6; Maz 73:3; halom adalah kesejahteraan material dan jasmani. Penggunaannya muncul dalam pengertian konteks sekuler pada sisi material (lihat Kej. Yer.6:14; Yesaya 57:18). Shalom juga diekspresikan dalam lingkup politik dan meliter, sperti dalam watu perang atau damai (Pkh. 3:8; IRj 2:5; Dan.10:19). Jadi shalom dalam perjanjian lama mencakup konsep sekuler dan keagamaan, atau yang dunia maupun saklar. Tidak ada dikotomi antara sacral dan duniawi, Shalom meliputi Rohani dan jasmani, adalah konsep yang holistic bagi Israel dalam Perjanjian Lama. Dasar Alkitabiah untuk memahami arti pelayanan holistic, setidaknya ada tiga pokok pendekatan yang akan menjelaskan hal 
tersebut : (1). Tujuan Allah yang mencakup seluruh ciptaan-Nya, (2). Manusia sebagai kesatuan dari tubuh, jiwa dan Roh yang tak teerpisahkan, dan (3). Kehidupan serta pelayanan Tuhan Yesus Kristus. Tujuan proklamasi Injil Yesus Kristus bukanlah sekedar mengubah manusia menjadi manusia religious yang memisahkan dirinya dari dunia, supaya dapat menikmati keselamatannya. Tetapi lebih kepada menjadikan komunitas orang yang mengaku Yesus Kristus adalah Tuhan atas seluruh kehidupan, kemudian hidup dalam terang Kristus. Komunitas tersebut bukan hanya berbicara tentang Kasih allah, tetapi juga mendemonstrasikannya secara konkrit melalui perbuatan-perbuatan baik baik yang telah Allah tetapkan sebelumnya bagi mereka (Ef.2:10). Sedangkan pendapat Myers yang dikutp Yamamori tidak jauh berbeda, medefenisikan pelayanan holistic sebagai pemberitaan Injil dan transformasi social : Holistik ministry as one in which compassion, social transpormation and proclamation are inseparably related. Dapat ditegaskan bahwa dimana Injil diberitakan disitu ada pembebasan manusia secara holistic, untuk menikmati shalom secara utuh pula.

\section{Dasar Teologis Misi Holistik}

Dalam bagian ini akan dibahas mengenai dasar misi holistik, baik dalam Perjanjian Lama, maupun Perjanjian Baru, juga dasar Eskhatologis.

\section{Kasih Allah Yang Universal}

Berbicara tentang misi, tidak dapat dilepaskan dari bagaimana sikap hati Allah yang dengan penuh kasih mencari dan menyelamatkan umat manusia yang telah jatuh ke dalam dosa. Kasih Allah tidak hanya terfokus kepada Adam dan Hawa sebagai manusia Pertama yang telah jatuh kedalam dosa, tetapi Allah telah melihat kepada masa kekekalan akan nasib manusia secara universal dimana keturunannya akan menanggung akibat dosa tersebut. Dalam hal ini kuiper mengatakan demikian :

Pada halaman -halaman Pertama kitab suci kita sudah diperlihatkan pada perbuatan-perbuatan Allah pada seluruh dunia,la bertindak secara universal.kisah penciptaan langit dan bumi dan penempatan manusia didalamnya merupakan pra sejarah bagi sejarah keselamatan untuk seluruh manusia dan dunia,fasal-fasal kejadian 1 sampai dengan dua adalah pendahuluan dan latar Belakang bagi sejarah Israel selanjutnya, yang bersifat universal.

Dalam hubungan ini, penting seperti apa yang di tulis dalam keluaran 19:56,'... .kamu akan menjadi harta kesayangan-Ku sendiri dari antara segala bangsa, sebab Akulah yang empunya seluruh bumi ''.selanjutnya Veronika Elbers menulis demikian :

Karena Allah menciptakan segala sesuatu (kej.1:27,2:27).itu srbabnya tidak ada Allah lain yang sanggup menyelamatkan manusia (Ul.4:39,Yes.44:6,45:21). Dia juga memiliki hak mutlak menguasai seluruh umat manusia, seperti dikatakan oleh kitab Roma 3:29,...."atau adakah Allah hanya Allah orang Yahudi saja? Bukankah la juga adalah Allah bangsa-bangsa lain?

Dia adalah Allah bagi semua manusia. Itu sebabnya la melarang manusia menyembah ilah-ilah lain. kasih Allah adalah kasih yang bertindak mencapai seluruh dunia. Allah adalah Allah yang missioner, mencari dan ingin menyelamatkan seluruh umat manusia tanpa pengecualian.J. Herbert kane menjelaskan:

The Christian mission, like the gospel, originated in the heart of God.lt is his work, not man, sand it grows out of his assential character. If God were anyother kind of God,there would be no Christian mission.The revelation of God in the sciptures are not concernedto prove the existence of God ; that is taken for granted.What the 
Bible reveals is the character of God.His person can never be divorced from his character.

Dalam kej.3:15, kasih Allah dinyatakan melalui suatu janji keselamatan bagi seluruh umat manusia di seluruh dunia. Keturunan perempuan akan membebaskan manusia dari dosa. Benih perempuan yaitu mesias akan melawan benih ular yakni si iblis.

Untuk mewujudkan kasih Allah yang mencari manusia berdosa, menuntut pengorbanan ; karena manusia berdosa memerlukan penebusan melalui pengorbanan Yesus Kristus di kayu salib (bandingkan Roma,3:23-24).George W.peters menulis :

Ada beberapa aspek keselamatan dalam kejadian 3:15:(1) keselamatan adalah tindakan Allah; Artinya Allah yang mengadakan keselamatan. (2). keselamatan itu bersifat konflik dengan kuasa gelap. (3). keselamatan mempunyai jangkauan mencakup seluruh umat manusia. (4). keselamatan akan datang melalui seorang pengantara, keselamatan itu terjadi melalui seorang penebus. (5). keselamatan itu akan terjadi dalam sejarah. Sebagai hamba Allah, Israel di tugaskan untuk menjadi saksi Allah dalam seluruh kehidupan mereka (bandingkan, Yes.55:4; Ul.28:9-10;Yes.49:31 Kel.19:61;Yes 51 :4). Mengenai hal ini Kuiper mengatakan bahawa : "Pemilihan atas Israel adalah jalan yang ditempuh Allah untuk mencapai tujuan-Nya yaitu pengakuan nama-Nya oleh sekalian bangsa”.

Dalam sejarah keselamatan, penyataan diri Allah secara universal melewati fasefase, mulai dari perjanjian dengan Nuh, Abraham, dan Daud.

\section{Perjanjian Dengan Nuh}

Perjanjian dengan Nuh dalam Kej. 8:21-9:8, merupakan janji yang universal, bukan saja kepada Nuh tetapi kepada seluruh makhluk. Dalam perjanjian ini Allah secara nyata mewujudakan kedaulatan-Nya dalam membagi anugerah-Nya kepada semua orang. Dalam hal ini Boeker mengatakan :

Tidak ada peran sedikitpun dari manusia dalam mengadakan perjanjian dengan Allah. Tanda pelangi diberikan bukan untuk mengingat manusia kepada perjanjian, melainakan untuk mengikat Tuhan pada perjanjian-Nya.

Nuh dan keluarganya mewakili umat manusia untuk menerima perjanjian keselamatan. Bahtera Nuh dan segala mahluk didalamnya menjadi bagian dari wujud keselamatan yang akan dianugrahkan Allah pada pasca air bah.

\section{Perjanjian Dengan Abraham}

Pangilan dan pilihan Allah datang pada Abraham, menghendaki dia segerah meninggalkan negri, sanak saudara ,dan rumah bapanya. Ttindakan ini menujukan bahwa dari pihak Allah sendiri yang berinisiatf, seperti edikatakan oleh Stepen Tong :

Selamanya bukan manusia yang mencari Allah ,melainkan Allah yang mencari manusia; bukan manusia yang memanggil Allah, melainkan Allah yang memanggil manusia .bukan pula manusia yang terlebih dahulu berseruh kepada Allah,melainkan Allah terlebih dahulu memperingatkan manusia. Bukan manusia yang terlebih dahulu memilih Allah, melainkan Allah yang terlebih dahulu memili manusia untuk diselamatkan.

Dalam kejadian 1-11 Perjanjian Allah difokuskan untuk semua bangsa, tetapi dalam kejadian 12:1-3, Allah memilih Abraham menjadi duta keselamatan untuk seluruh umat 
manusi. Nampak disini tujuan Allah tetap sama, bersifat universal, hanya setrateginyab yang berbeda. Perbedaanya ialah karena Allah memilih pribadi yang kelak dari ketuerunanya, berkat Allah sampai kepada umat manusia. Mengenai hal ini peters mengemukakan tiga hal penting dalam pemilihan Abraham (kej. 12:1-3 ),yaitu:

- Lewat pemilihan Abraham, lahirlah bangsa Israel. Allah membatasi diri memakai Abraham dan keturunannya yaitu bangsa Israel sebagai saluran berkat-Nya.

- Lewat pemilihan Abraham, Allah menjadi Bapa Israel, semua bangsa harus datang kepada Israel dan melalui Israel mereka dapat mengenal Allah.

- Melalui pemilihan Abraham, moral dan pengetahuan tentang Allah lebih jelas.

\section{Perjanjian Dengan Musa}

Perjanjian Allah dengan Musa di gunung Sinai, merupakan suatu perwujudan hubungan Allah dengan Israel sebagai bangsa pilihan -Nya, yang telah dipilih sebelumnya oleh Allah dengan tujuan untuk menebus dan mengangkat Israel sebagai anak (kel .2:25;6:6-8; 2:22). Hal ini merupakan kelanjutan penggenapan perjanjian dengan Abraham. Dalam perjanjian ini Allah sendiri yang berinisiatf untuk mengikat diri -Nya dengan Israel sebagai bangsa piliha-Nya. Perjanjian ini mengikat Israel dalam ketaatan kepada Allah dalam hubungan yang bersifat rohani (kel .6:7), dan jika Israel kedapatan melanggar perjanjian itu, mereka akan menerima hukuman (kel .20:5 ; 20:7; 22:20).

Hal ini menunjukan bahwa existensi Israel sebagai suatu bangsa, tergantung kepada ketaatan mereka terhadap perjanjian dengan Allah. Perjanjian Allah dengan Israeldi Sinai bertujuan supaya mereka dapat dipakai sebagai saluran berkat bagi semua bangsa. Hal ini menggambarkan sebagai hamba Allah, Israel ditugaskan untuk menjadi saksi Allah dalam saluran kehidupan mereka (bdgkan. Yes .55:4; Ul. 28:9-10; Tes. 49:3; Kel. 19:6; Yes. 51:4). Mengenai hal ini kuiper mengatakan : "pemeliharaan atas Israel adalah jalan yang ditempuh Allah untuk mencapai tujuan-Nya yaitu pengakuan nama-Nya oleh sekalian bangsa.

Pemilihan Israel tidak sekali-kali bertujuan egoisme agar hanya bangsa Israel yang menerima keselamatan, melainkan bertujuan universal. Dengan memilih umat Israel maka Allah mengarahkan pandangan-Nya kepada seluruh dunia.

\section{Perjanjian dengan Daud}

Perjanjian Allah dengan Daud difirmankan melalui nabi Natan dalam II Samuiel 7:12-17. Dalam Mazmur 85:4-5, 28-29, perjanjian yang diberikan kepada Daud sama dengan perjanjian kepada Abraham, dimana sifatnya yang abadi berdasarkan inisiatif Allah menjadi jelas. Dalam perjanjian dengan Daud muncul suatu unsur yang baru yaitu: unsur yang menonjol dalam perjanjian ini adalah menunjuk kepada Mesias yang adalah inti perjanjian baru. Mengenai hal ini TGR Boeker mengatakan : "Mesias bukan hanya salah satu unsur dalam perjanjian Allah yang baru, melainkan Mesias sendiri adalah (personafikasi) perjanjian Allah. Misi dalam perjanjian lama tidak hanya terfokus pada umat Israel, namun berkembang sampai kepada orang kafir. Hal ini tergambar jelas dalam kitab-kitab sejarah yang menunjukan dengan jelas kerinduan Allah atas umatNya. Dalam segala situasi peristiwa sejarah, dimana Allah memakai bangsa-bangsa kafir untuk meolong umat-Nya bahkan mewujudkan rencana keselamatan bagi mereka. (bd. Rut, 4:21-22, Mat. 1:15) 
Dalam kitab-kitab puisi, kebenaran Allah digambarkan sebagai pencipta dan penopang dunia. Dia adalah raja dan penguasa. Kitab mazmur adalah salah satu kitab puisi yang mengambarkan dengan jelas tujuan misi Allah bagi orang kafir. (bd. Maz. 96:1-3).

Misi dalam kitab-kitab Nabi diwujudkan melalui dan panggilan seseorang. Nabi dipilih dan diangkat oleh Allah untuk mengingat umat-Nya agar mereka menaati perintah Allah, supaya dapat menjadi berkat bagi bangsa-bangsa lain. Hal yang menonjol dalam pemberitaan para Nabi adalah pengharapan Mesianis yang akan menyelamatkan seluruh umat manusia. Pemberitaan dan pelayanan para Nabi tidak hanya pengharapan Mesianis yang akan menyelamatkan seluruh umat manusia. Pemberitaan dan pelayanan para Nabi tidak hanya kepada bangsa Israel saja tetapi juga kepada bangsa-bangsa kafir, misalnya pelayanan Nabi Yunus kepada orang Niniwe. Pelayanan para Nabi ditandai dengan visi yang jelas.

Dari semua uraian diatas, dapatlah disimpulkan bahwa perjanjian lama adalah buku misi, karena perjanjian lama merupakan keseluruhan misi Allah kepada umat manusia. Dengan Israel sebagai alat misi. Misi Allah dalam perjanjian lama bersifat sentrifugal dimana Israel sebagai objek pengenalan akan Allah. Mengenai hal ini Kuiper mengatakan:

Israel mempunyai fungsi sebagai perantara dalam rencana Allah. la harus menerima dengan taat, janji-Nya dan hukum-Nya supaya dapat memperlihatkan kepada bangsa lain, siapa Allah Israel. Fungsinya tidak lain, daripada menjadi daya penarik

Ada satu hal yang sampai saat ini masih belum dipahami oleh kebanyakan orang Israel, yaitu bangsa dalam nubuat para Nabi, janji tentang kedatangan Mesias merupakan inti dari berita mereka, namun bangsa Israel terlalu lamban untuk percaya. "Yesus puncak wahyu Allah yang dinyatakan melalui bangsa Israel, lahir dari keturunan Daud yang disebut tunas Isai"

\section{Manifestasi Kasih Allah Bagi Segala Suku Bangsa.}

Dalam diri Yesus, kasih Allah yang universal digenapi untuk menyelamatkan setiap manusia yang mau menerima-Nya, dan juga menyelamatkan bagi alam semesta. Didalam diri Yesus Kristus, karya perdamaian dinyatakan dimana setiap orang yang percaya kepada-Nya tidak akan binasa, tetapi beroleh hidup yang kekal (Yoh. 3:16; 14:67).

Dalam perjanjian baru, kata a " diutus untuk berbicara yang dikatakan ialah tentang kesukaan atau syaloom (Karl Hendrich, 1979: 403-404). Kata "Apostelle" berbicara tentang pengutusan Kristus oleh Allah (Mat. 10:40), pengutusan Roh Kudus oleh Yesus Kristus (Luk. 24: 49), pengutusan murid-murid oleh Yesus (Yoh. 20:21). Sedangkan penggunaan pempo dalam Roma $8: 3$ (Allah mengutus Anak-Nya), Yohanes $14: 26$ ( pengutusan Roh Kudus), Yohanes 1: 33 ( Pengutusan Yohanes pembabtis).

Mengacu pada pengertian kedua kata diatas, maka makna yang dimaksudkan adalah 'pengutusan seseorang atau kelompok ke suatu tempat untuk melakukan sesuatu'. Kata misi lebih spesifik lagi diterjemahkan dalam perjanjian baru. "Pelayan Injil baik melalui kata-kata (Firman) atau perbuatan.

Dengan demikian yang dimaksud dengan misi dalam perjanjian baru adalah "pengutusan untuk melakukan pekerjaan pemberitaan Injil baik melalui perkataan 
maupun melalui perbuatan". Yang dimaksud adalah terutama Yesus Kristus sendiri yang telah diutus Allah Bapa untuk menyelamatkan umat-Nya, kemudian para Rasul yang dipilih dan diutus oleh Yesus dan orang percaya yang diutus untuk menyelamatkan syaloom kepada dunia (orang yang belum percaya.

\section{Dalam Pelayanan Yesus}

Kitab-kitab Injil secara jelas dan rinci telah menceritakan tentang kehadiran Tuhan Yesus, pelayanan-Nya, sampai pada kematian-Nya, kebangkitan dan kenaikan ke Sorga. Mengenai hal, ini Tallman mengatakan bahwa, "This distinction between the gospels substantiates the missionary perpective of the New Testament. It particulary affiras :

- God's interstin the sharing of his son's life with the whole word; 2. God's desire that thisngood news be communicated. 3. God's concern for the needs of each people group. 4. God's nonprejudical treatmen of all peoples in His redemptive program

Tujuan misi Yesus Kristus dalam kitab-kitab Injil, pertama adalah untuk orang Israel (Mat. 5:29), kemudian tertuju kepada seluruh dunia. Pemberitaan dan tindakan Tuhan Yesus terhadap orang-orang kafir merupakan kebalikan mutlak dari proselitisme Yahudi (Kuiper, 1985 : 37). Disamping itu dalam Injil-injil synopsis (Matius, Markus dan Lukas), kita dapat membaca cerita mengenai pertemuan Yesus dengan orang-orang kafir (bangsa-bangsa lain). Misalnya perjumpaan Yesus dengan penghulu lascar di Kapernaum (Mat. 8:5-10), Yesus dengan perempuan Yunani bangsa Siro-Finisia (Mrk. 7:24-30; Mat 15:21-28. Dalam perjumpaan Yesus dengan lascar di Kapernaum, la heran dan berkata "sesungguhnya iman sebesar ini tidak pernah Aku jumpai pada seorangpun diantara orang Israel" (Mat. 8:10).

Dalam hal ini orang-orang Yahudi disebut anak-anak oleh Yesus, padahal yang dari bangsa-bangsa lain disebut sebagai anjing-anjing, namun demikian ia meluluskan permintaan mereka juga. Dengan menyembuhkan orang-orang sakit dari bangsa lain, maka Yesus mendekatkan jurang, agar bangsa-bangsa lain dapat melihat dan menikmati karya keselamatan didalam diri Yesus. Penyembuhan-penyembuhan-Nya barulah bersifat tanda, tetapi tanda itu menunjuk kepada masa depan yang penuh dengan janji Allah yang akan berlaku juga bagi orang-orang kafir. Dalam hal ini David W. Ellis menjelaskan :

Manifestasi Yesus Kristus merupakan jawaban Allah terhadap penderitaan dunia.

Maka Missio Dei adalah manifesasi Kristus kepada dunia dan untuk megerti misi Gereja, kita harus mengerti hal ini.

Sasaran pelayanan Tuhan Yesus tidak pernah ditujukan hanya untuk satu bangsa, golongan atau kelompok tertentu saja, tetapi secara universal untuk semua orang. Hal ini Nampak jelas pada warisan amanat Agung yang diwariskan Yesus kepada muridmurid-Nya, seperti dijelaskan oleh Kueper demikian :

Sasaran amanat Agung Tuhan Yesus, tidak pernah untuk satu suku atau satu bangsa saja, melainkan untuk segala bangsa dan seluruh dunia. Allah tidak menghendaki seorangpun binasa (2 Petrus 3:9), melainkan Allah menghendaki segala suku dan kaum bangsa, dan bahasa kelak akan berdiri dihadapan Tahta di hadapan Anak Domba Allah serta berseru : "Keselamatan bagi Alah kami yang duduk diatas Tahta, dan bagi anak Domba “( Why. 7:7-10). 
Kenyataan menunjukan bahwa Yesus tidak terikat pada batas-batas kebangsaan, kebiasaan, keagamaan. la datang menyelamatkan pemungut cukai dan orang berdosa (Mat. 9 : 9-13), bertentangan sekali dengan parikulrisme Yahudi yang menganggap bangsa lain sebagai kafir yang tidak layak untuk menerima keselamatan. Yesus tidak menjauhkan diri dari orang-orang sakit, yang dianggap haram dalam agama Yahudi.

Demikian juga perempuan pelacur dan orang berdosa lain tidak dianggap-nya rendah, bahkan justru mereka itulah yang la tolong. Orang seperti perempuan Samaria tidak lepas dari perhatian-Nya (Luk. 10; 17:11-19; Yoh. 4). Yesus juga tidak segan-segan menjelajahi keluar negeri, artinya ke wilayah orang-orang kafir (bangsa-bangsa yang bukan Yahudi), yaitu ke Tirus (Mark. 7:24) dank e Kaisarea (Filipi 8:27) dan sering juga la melintasi daerah di seberang Yordan. " Bahkan pada permulaan pekerjaan-Nya, la pindah dari Nazareth ke Kapernaum, karena kota itu terletak di jalan ke danau Galilea, wilayah bangsa-bangsa lain menjadi masyur sampai keseluruh benua Syam (siria), dan dimana-mana ada orang mengikuti Dia.

\section{Dalam Pelayanan Para Murid (Rasul-Rasul)}

Misi dalam Kisah Para Rasul dimulai dengan adanya pencurahan Roh kudus (Kis. 2:1-13). Roh kudus berperan penting dalam pekerjaan misis. Mengenai hal ini Harold Cook mengatakan : "Perjanjian baru memperkenalkan Roh Kudus sebagai pelopor dan Faktor pengatur misi......." . Para Rasul memulai pelayanan mereka dari Yerusalem sesudah itu ke Samaria (Kis. 8: 25-36), kemudia berkembang sampai ke Roma, dan akirnya sampai ke Eropa.

Dalam hal ini terlihat jelas, bagaimana para murid melaksanakan amanat yang disampaikan oleh Yesus kepada mereka untuk menjangkau orang-orang kafir, suku bangsa lain yang ada disekitar mereka. Pusat Injil memang Yerusalem, tetapi penyebaran Injil harus sampai kepada suku bangsa lainnya bahkan sampai ke ujungujung bumi.

Yesus berkata kepada murid-Nya : " Karena itu pergilah “. Penulis Injil dalam

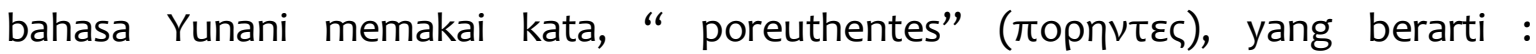
" Meninggalkan, menyeberang, batas", yaitu batas sosial, batas ras, batas kebudayaan, batas giografis ( Verkuyl, 1979 : 107). Pengertian ini sangat penting bagi para murid dalam tugas mengkomunikasikan Injil Yesus Kristus. J. Herbert Kane katakan bahwa dalam hidup para murid, ada tiga pengalaman yang penting bersama Yesus, yang dapat diringkas dengan tiga kata yaitu : "Come" (Mat. 11 : 28). " Follow " (Mat. 16 : 24-25), "Go" ( Mat. 28 :18-20). "all Three words are really part of the great commission “

Kata " pergilah " tidak hanya menjelaskan bahwa Yesus mengutus murud-muridNya untuk pergi keseluruh dunia, tetapi juga merupakan pernyataan bahwa mereka tidak akan tinggal untuk persekutuan mereka sendiri. Mereka akan disebar luaskan dengan cara biasa maupun lewat penderiataan supaya mereka sampai pada seluruh wilayah kerajaan (Kis. Rasul 8:4; 1:19-21).

Para rasul juga pergi secara terencana dalam melaksanakan Amanat Agung Yesus Kristus. Salah satu aspek yang penting dalam pelayanan Paulus ialah: ia pergi dengan rencana dan strategi yang tepat. Misalnya sebelum pergi ke Roma, ia telah merencanakannya dengan sungguh-sungguh ( Roma 15:23-24 ). Dalam merencanakan 
dan mengatur strategi pelayanan, Paulus tetap sensitive dan terbuka terhadap pimpinan Roh Kudus, Deans, Gilliland mengatakan:

More than coce Paul's plans did not coincide eith the divide plan of God (Acts 16:7; Rom. 15:22). But Such Conflicts only seve to show that his own designs were adaptable ti the higher mind of the spirit. lit does not mean that he did no planning where he would visit, how he would make his first contacs, or how he would communicate in a givin place. To all these things Paul gave careful attention, but God had final say.....it is more accurate to speak of a strategis element in Paul's ministry, because his work was not always of the own choosing. This sensitive combination of the of the and the divine could be described as the miracle of mission.

Para Rasul dan Gereja mula-muladipanggil tidak hanya untuk bersekutu dengan Tuhannya, melainkan dipanggil untuk melayani, “ jadikanlah semua bangsa muridku”. Sasarannya adalah : semua bangsa” ( panta taethne), dan dalam bagian lain dipakai istilah : " ujung-ujung bumi " dan dimaksudkan kepada segala gansa di setiap letak geografis.

Kata " semua bangsa” ( All nations ), juga dimaksudkan " segala keberadaan manusia”. Jadi semua bangsa dengan segala keberadaannya harus dicapai untuk dijadikan murid Kristus. Dalam hal ini Verkuyl berkata demikian: “ The Gospel must go aut to all human beings wherever they live. They must be gaehered as the first of a new humanity"

Dengan demikian pemahaman tentang amanat Agung tidak hanya dipahami dari segi pemberitaan Injil ( PI ), melainkan merupakan tugas yang " Comprehensive" dari Gereja dan umat Tuhan yaitu setiap orang percaya untuk menjadikan segala bangsa murid Tuhan. Amanat Agung adalah mandat Yesus Kristus dan merupakan keseimbangan dari tugas yang sama, yang ia terima dari Bapa-Nya." Sama seperti Bapa mengutus Aku, demikian juga sekarang Aku mengutus kamu“ (Yohanes 20:21). Bahkan la sendiri adalah Amanat Agung itu sendiri, yang diutus oleh Allah (Yohanes 3:16) untuk melayani (Markus 10:45) dan membawa manusia mengalami kembali damai sejahtera dengan Allah.

\section{Dasar Eskhatologis}

Alkitab dengan jelas memberitahukan bahwa Injil kerajaan itu akan diberitakan di seluruh dunia, agar sekalian bangsa dapat mendengar Injil, sesudah itu barulah tiba kesudahannya (Mat. 24:24 ). Jadi apakah yang harus dilakukan oleh orang-orang yang mengharapkan kedatangan Tuhan kembali? ", ada dua hal yang harus kita lakukan: yang pertama, menyucikan diri, dan yang kedua menyelesaikan pekerjaan-Nya melalui pemberitaan Injil kepada segala suku bangsa diseluruh muka bumi ini“. Selanjutnya Stepen Tong berkata:

Kita harus memberitakan Injil sampai Kristus datang kembali. Karena kedatangan Kristus kali yang kedua itu bukan dengan status juruselamat, bukan lagi utusan perdamaian, melainkan sebagai hakim yang terakhir, penghakiman Yang Maha Kuasa. Itu sebabnya kita harus memberitakan Firman Tuhan dengan serius, menasehati orang agar bertobat dan kembali kepada Kristus.

Dalam pemberitaan para Nabi perjanjian lama, selalu ada pengharapan bahwa bangsa-bangsa lain akan dihimpun kedalam pusat kehadiran Allah Israel, dan mereka (bangsa-bangsa lain itu ), akan mengaku nama-Nya. Kuiper mengatakan: 
Keselamatan Eskhatologis digambarkan tentang datangnya ber-arak-arakan bangsabangsa, satu pawai yang besar ke arah Sion, ke arah „, pesta raya Oikumene“. Kedatangan itu merupakan gerakan yang sentripetal (pusaran ), menuju ke pusat dimana tersedia keselamatan dimana ada Yahwe dan umat-Nya, pusat kehadiran-Nya, pusat dunia. Bangsa-bangsa akan datang kepada Israel dan Allah-Nya; sam=bil mencari: gunung tempat rumah Tuhan ( Yes.2:2-3; Mikha 4:1-2; Yes. 18:7) taruk dari pangkal Isai ( Yes.11:10 ) perjumpaan di gunung Sion ( Yes. 25:6-8), terang sion ( Yes. 60 ) Yerusalem ( Yes. 66:20 ; Yer. 3:17; Mikha 7:12 ). (1985:21).

Dalam perjanjian baru, kitab Wahyu merupakan suatu pernyataan bagi seluruh bangsa, dimana klimaks dari tujuan misi Allah dinyatakan dalam Wahyu 7:9, " kemudian dari pada itu aku melihat, sesungguhnya suatu kumpulan besar orang banyak yang tak terhitung banyaknya, dari segala bangsa dan suku, dan kaum dan bahasa, berdiri dihadapan tahta dan dihadapan anak domba ....". selain dari pada itu Tallman menyebutkan bahwa:

The concluding book of the Bible, revelation, must also be mentioned as providing a picture of the climaks judgment, tretribution, vindication, righteousness, peace, and rewaed all join together in this dramatic last hour human history. At last, he the end, " I am the last", accomplishes all of his purpose.

Pemberitaan Injil harus mengarah dan tertuju pada satu tujuan utama, yaitu keselamatan kekal didalam Tuhan Yesus Kristus. Yeuss berkata : " Dan ketahuilah, Aku menyertai kamu senantiasa sampai kepada akhir jaman “ ( Mat.28:20 ). Ucapan ini mengandung makana, penginjilan harus dilakukan terus saat dunia ini berakhir.

Dengan demikian suku Enim sebagai bagian dari umat kepunyaan Allah yang telah terhitung dalam penyelamatan tetapi telah menjadi tawanan kegelapan, wajib dan berhak atas berita syalom, pembebasan dari Allah. Karena hati Allah mengasihi segala suku bangsa dan kaum di dunia ini tanpa memandang latar belakang dan perbedaan Ras, sebab semua mahluk di dunia ini adalah ciptaan Allah (Kel. 19:5 ; Maz. 2:8; 1 Kor. 10:26).

\section{Kesimpulan}

Misi itu sendiri adalah karya Allah bagi keselamatan manusia didunia yang sudah jatuh kedalam dosa yang dimulai dari diri Allah sendiri (Misio Dei), dimana la datang ke Taman Eden untuk mencari dan memanggil Adam dan Hawa. Karya Allah bukan saja memulihkan manusia yang berdosa secara Rohani, akan tetapi terjadi juga pemulihan secara fisik, dimana manusia yang sudah kehilangan Kemuliaan Allah (mereka telanjang), kemudian merajut pakaian dari daun kulit binatang untuk menutupi aurat mereka.

Pemulihan manusia berdosa mencakup seluruh eksistensi hidup manusia itu sendiri baik fisik jasmani dan Rohani. Adam dan Hawa menerima hukuman akibat dosa yang telah mereka perbuat, namun Allah memberikan kesempatan untuk mereka dipulihkan kembali dengan tetap memberikan mandat budaya untuk menguasai bumi, meskipun harus dengan berkeringat mencari nafkah dan harus sakit pada seorang ibu dalam melahirkan.

Dalam Pelayanan para Nabi dan Rasul dengan jelas memperlihatkan bahwa kehadiran Hamba-hamba Tuhan dan orang percaya ditengah dunia ini membawa berita Shaloom dari Allah yang berdampak pada kesejahteraan umat umumnya seperti Yusuf, Nabi Yeremia. 
Tuhan yesus memberikan teladan yang sangat jelas dalam pelayanan-Nya, bahwa pemulihan manusia seutuhnya harus memperhhatikan segi rohani yang utama tetapi juga memulihkan kehidupan social, Jasmani karena itulah makna dari kabar baik Keselamatan. Yesus membawa manusia untuk bertemu dengan diri-Nya sebagai Tuhan dan juruselamat, akan tetapi la juga menyembuhkan dan memulihkan ksakit penyakit mereka, bahkan memberi mereka yang lapar dengan makanan. Itulah berita injil yang Holistik. 


\section{Kepustakaan}

Arie de Kuiper,

1985 Misiologia, Jakarta: BPK Gunung Mulia,

2003 Misiologia, Jakarta: BPK Gunung Mulia,

David R. Brougham,

T.th

Merencanakan Misi lewat Gereja, Malang : Gandum Mas,

David W. Ellis,

1989 Metode Penginjilan, Jakarta: Yakombinkas,

Dean Gilli S Gilliland,

1983 Paulin Theologi \& Mission Practice, Michigan :Baker Book House,

George Peters Wagner,

1981 A Biblical Theologi of mission, Chicago : Moody Press,

Herbert J. Kane,

$1982 \quad$ Understanding Christian Mission Third Edition, Grand Rapids,

Herlianto,

1998 Pelayanan Perkotaan. Bandung : Yabina,

J. Verkuyl,

1986 Contemporer Misiologi Christian Mission, Jakarta: BPK Gn. Mulia,

Rane C. Padilla, 2004 "Holistic mission" Occasional paper No.33, Lausane committee for world Evangelization,

Raymond J. Tallman,

1989 An Introduction To World Mission, Chicago: Moody Prees,

Stephen Tong,

1988 Teologi Penjilan, Jakarta: Lembaga Reformed Injili Indonesia,

Tetsunao Yamamori, Bryant L. Myers \& David conners (eds),

1995 serving With The Poor In Asia, Monrovia, CA : MARC,

TGR. Boeker,

1992 Tema-tema Perjanjian Lama, Batu: Dept.Literatur YPPII,

The root meaning of the verb shalem better expreses the true concept of shalom : completeness, wholeness, harmony, fulfillment : R. Laird Harris, Gleason L. Archer, Jr, Bruce K. Waltke (eds),

1980 Theological Word book of the old Testament Vol 2 (Chicago : Moody press,.

Tim publikasi ICDS (ed),

2003 Misi holistic, (Jakarta: Institut for community and development studies

Veronika. J. Elbers,

1992 Teologia Misi, (Batu: Dept. Literatur YPPII,

Yakob Tomatala,

2003 Teologi Misi., YT Leadership Foundation, Jakarta, 